\title{
Nonlinear quasi-contractions in non-normal cone metric spaces
}

Shujun Jiang ${ }^{1}$ and Zhilong $\mathrm{Li}^{2,3 *}$

${ }^{*}$ Correspondence: |z|771218@sina.com

${ }^{2}$ School of Statistics, Jiangxi University of Finance and

Economics, Nanchang, 330013, China

${ }^{3}$ Research center of Applied Statistics, Jiangxi University of Finance and Economics, Nanchang, 330013, China

Full list of author information is available at the end of the article

\begin{abstract}
In the paper, we prove a new fixed point theorem of nonlinear quasi-contractions in non-normal cone metric spaces, which partially improve the recent results of Arandelović and Kečkić's and of Li and Jiang since some of the essential conditions therein are removed. A suitable example is presented to show the usability of our theorem. It is worth mentioning that the results in this paper could not be derived from the corresponding results in the setting of metric spaces by using a scalarization function or a Minkowski functional.
\end{abstract}

MSC: $06 \mathrm{~A} 07 ; 47 \mathrm{H} 10$

Keywords: nonlinear quasi-contraction; non-normal cone metric space

\section{Introduction}

In 2007, Huang and Zhang [1] introduced the concept of cone metric spaces, as a generalization of metric spaces, and gave the version of the Banach contraction principle and other basic theorems in the setting of cone metric spaces. Later on, by omitting the assumption of normality of the cone, Rezapour and Hamlbarani [2] improved the relevant results of [1], and presented a number of examples to support the existence of non-normal cones, which shows that such generalizations are meaningful. Since then, many authors have been interested in the study of fixed point results in non-normal cone metric spaces; see [3-17]. In the preceding references except $[3-5,16,17]$, the involving contractions are always assumed to be restricted with a constant.

There are some references concerned with the problem of whether cone metric spaces are equivalent to metric spaces in terms of the existence of the fixed points of the mappings in cone metric spaces; see [7-10]. Actually, it has been shown that each cone metric space $(X, d)$ is equivalent to a usual metric space $\left(X, d_{e}\right)$, where the real-valued metric function $d_{e}$ is defined by a nonlinear scalarization function [8] or by a Minkowski functional [9]. Besides, it has been pointed out in [18] that many fixed point generalizations obtained in cone metric spaces are not real generalizations, and the authors should take care in obtaining real fixed point generalizations in cone metric spaces.

In 1974, Cirić [11] introduced Ćirić's quasi-contractions in metric spaces as one of the most general classes of contractive-type mappings, and proved the well-known theorem that every Ćirić's quasi-contraction $T$ has a unique fixed point, which was then generalized to cone metric spaces by [13-15]. There were many works concerned with the fixed point results of contractions or quasi-contractions restricted with nonlinear comparison func-

C 2014 Jiang and Li; licensee Springer. This is an Open Access article distributed under the terms of the Creative Commons Attribution License (http://creativecommons.org/licenses/by/2.0), which permits unrestricted use, distribution, and reproduction in any medium, provided the original work is properly cited. 
tions, we refer the readers to [19-25]. Recently, Arandelović and Kečkić [16] considered nonlinear quasi-contractions in cone metric spaces, and by using the nonlinear scalarization method of $\mathrm{Du}$ [8], they obtained several fixed point theorems of nonlinear quasicontractions and quasi-contractions restricted with linear contractive bounded mappings in cone metric spaces over locally convex Hausdorff topological vector spaces with the assumption that $(I-A)(\operatorname{int} P) \subset \operatorname{int} P$. Very recently, Li and Jiang [17] removed the contractive condition of linear bounded mappings appearing in [16], and they proved a fixed point result of quasi-contractions restricted with linear bounded mappings in non-normal cone metric spaces at the expense of

$$
u_{n} \stackrel{w}{\rightarrow} \theta \Rightarrow A u_{n} \stackrel{w}{\rightarrow} \theta, \quad \forall\left\{u_{n}\right\} \subset P .
$$

In this paper, we first show that every nondecreasing mapping $A: P \rightarrow P$ satisfies the condition ( $\mathrm{H}$ ) provided that it is continuous at $\theta$ and $A \theta=\theta$ (see Lemma 3), and consequently, the condition $(\mathrm{H})$ in [17] is superfluous and could be omitted; see Remark 1 . Then by using Lemma 3, we prove a new fixed point theorems of nonlinear quasi-contractions in non-normal cone metric spaces, which improved the relevant results of $[16,17]$ since the conditions $(I-A)(\operatorname{int} P) \subset \operatorname{int} P$ and $(\mathrm{H})$ are removed. In addition, a suitable example is presented to show the usability of our theorem.

It is worth mentioning that the results in this paper could not be derived from the corresponding results in the setting of metric spaces by the methods of $[8,9]$ and also cannot be obtained by any existing fixed point results in cone metric spaces. Hence the results in this paper are real generalizations.

\section{Preliminaries}

Let $(E,\|\cdot\|)$ be a normed vector space. A cone of $E$ is a nonempty closed subset $P$ of $E$ such that $a x+b y \in P$ for each $x, y \in P$ and each $a, b \geq 0$, and $P \cap(-P)=\{\theta\}$, where $\theta$ is the zero element of $E$. A cone $P$ of $E$ determines a partial order $\preceq$ on $E$ by $x \preceq y \Leftrightarrow y-x \in P$ for each $x, y \in X$. In this case $E$ is called an ordered normed vector space.

A cone $P$ of a normed vector space $E$ is solid if int $P \neq \emptyset$, where int $P$ is the interior of $P$. For each $x, y \in E$ with $y-x \in \operatorname{int} P$, we write $x \ll y$. Let $P$ be a solid cone of a normed vector space $E$. A sequence $\left\{u_{n}\right\}$ of $E$ weakly converges [5] to $u \in E$ (denote $u_{n} \stackrel{w}{\rightarrow} u$ ) if for each $\epsilon \in \operatorname{int} P$, there exists a positive integer $n_{0}$ such that $u-\epsilon \ll u_{n} \ll u+\epsilon$ for all $n \geq n_{0}$.

A cone $P$ of $E$ is normal if the unit ball is order-convex, which is equivalent to the condition that there is some positive number $N$ such that $x, y \in E$ and $\theta \preceq x \preceq y$ implies that $\|x\| \leq N\|y\|$, and the minimal $N$ is called a normal constant of $P$. Another equivalent condition is that

$$
\inf \{\|x+y\|: x, y \in P \text { and }\|x\|=\|y\|=1\}>0 .
$$

Then it is not hard to conclude that $P$ is non-normal if and only if there exists a sequence $\left\{u_{n}\right\},\left\{v_{n}\right\} \subset P$ such that

$$
u_{n}+v_{n} \stackrel{\|\cdot\|}{\rightarrow} \theta \quad \nRightarrow \quad u_{n} \stackrel{\|\cdot\|}{\rightarrow} \theta
$$


which implies that the sandwich theorem does not hold in the case that $P$ is non-normal. However, in the sense of weak convergence, the sandwich theorem still holds even if $P$ is non-normal, and we have the following lemma.

Lemma 1 (see $[6,17])$ Let $P$ be a solid cone of a normed vector space $(E,\|\cdot\|)$ and $\left\{u_{n}\right\},\left\{v_{n}\right\},\left\{z_{n}\right\} \subset E$. If

$$
u_{n} \preceq z_{n} \preceq v_{n}, \quad \forall n,
$$

and there exists some $z \in E$ such that $u_{n} \stackrel{w}{\rightarrow} z$ and $v_{n} \stackrel{w}{\rightarrow} z$, then $z_{n} \stackrel{w}{\rightarrow} z$.

Lemma 2 (see [5]) Let $P$ be a solid cone of a normed vector space $(E,\|\cdot\|)$. Then for each sequence $\left\{u_{n}\right\} \subset E, u_{n} \stackrel{\|\cdot\|}{\rightarrow} u$ implies $u_{n} \stackrel{w}{\rightarrow} u$.

Lemma 3 Let $P$ be a solid cone of a normed vector space $(E,\|\cdot\|)$ and $A: P \rightarrow P$ a nondecreasing mapping. If $A$ is continuous at $\theta$ and $A \theta=\theta$, then it satisfies $(\mathrm{H})$.

Proof Let $\left\{u_{n}\right\}$ be a sequence of $P$ such that $u_{n} \stackrel{w}{\rightarrow} \theta$. It suffices to show $A u_{n} \stackrel{w}{\rightarrow} \theta$.

Fix $\epsilon \in \operatorname{int} P$. It is clear that $\frac{\epsilon}{m} \in \operatorname{int} P$ for each $m$. From $u_{n} \stackrel{w}{\rightarrow} u$ we find that, for each $m$, there exists $n_{m}$ such that $u_{n} \ll \frac{\epsilon}{m}$ for each $n \geq n_{m}$. Since $A$ is nondecreasing, $A u_{n} \preceq A\left(\frac{\epsilon}{m}\right)$ for each $n \geq n_{m}$. Note that $\frac{\epsilon}{m} \stackrel{\|\cdot\| \|}{\rightarrow} \theta(m \rightarrow \infty)$, then $A\left(\frac{\epsilon}{m}\right) \stackrel{\|\cdot\|}{\rightarrow} \theta(m \rightarrow \infty)$ since $A$ is continuous at $\theta$ and $A \theta=\theta$. Hence by Lemma $2, A\left(\frac{\epsilon}{m}\right) \stackrel{w}{\rightarrow} \theta(m \rightarrow \infty)$, which implies that, for each $c \in \operatorname{int} P$, there exists $m_{0}$ such that $A\left(\frac{\epsilon}{m}\right) \ll c$ for each $m \geq m_{0}$. Therefore we have $A u_{n} \ll c$ for each $n \geq u_{m_{0}}$, i.e., $A u_{n} \stackrel{w}{\rightarrow} \theta(n \rightarrow \infty)$. The proof is complete.

Remark 1 Every linear bounded mapping $A: P \rightarrow P$ is certainly nondecreasing and continuous at $\theta$, and hence it satisfies the condition (H) by Lemma 3. Therefore in Theorem 1 of [17], the condition $(\mathrm{H})$ is superfluous and could be omitted.

Let $X$ be a nonempty set and $P$ be a cone of a topological vector space $E$. A cone metric on $X$ is a mapping $d: X \times X \rightarrow P$ such that, for each $x, y, z \in X$,

(d1) $d(x, y)=\theta \Longleftrightarrow x=y$;

(d2) $d(x, y)=d(y, x)$;

(d3) $d(x, y) \preceq d(x, z)+d(z, y)$.

The pair $(X, d)$ is called a cone metric space over $P$. A cone metric $d$ on $X$ over a solid cone $P$ generates a topology $\tau_{d}$ on $X$ which has a base of the family of open $d$-balls $\left\{B_{d}(x, \epsilon)\right.$ : $x \in X, \theta \ll \epsilon\}$, where $B_{d}(x, \epsilon)=\{y \in X: d(x, y) \ll \epsilon\}$ for each $x \in X$ and each $\epsilon \in \operatorname{int} P$.

Let $(X, d)$ be a cone metric space over a solid cone $P$ of a normed vector space $E$. A sequence $\left\{x_{n}\right\}$ of $X$ converges $[1,5]$ to $x \in X$ (denote by $x_{n} \stackrel{\tau_{d}}{\rightarrow} x$ ) if $d\left(x_{n}, x\right) \stackrel{w}{\rightarrow} \theta$. A sequence $\left\{x_{n}\right\}$ of $X$ is Cauchy [1,5], if $d\left(x_{n}, x_{m}\right) \stackrel{w}{\rightarrow} \theta$. The cone metric space $(X, d)$ is complete [1,5], if each Cauchy sequence $\left\{x_{n}\right\}$ of $X$ converges to a point $x \in X$.

\section{Main results}

Let $P$ be a solid cone of a normed vector space $(E,\|\cdot\|)$. A mapping $T: X \rightarrow X$ is called a quasi-contraction, if there exists a mapping $A: P \rightarrow P$ such that

$$
d(T x, T y) \leq A u, \quad \forall x, y \in X,
$$


where $u \in\{d(x, y), d(x, T x), d(y, T y), d(x, T y), d(y, T x)\}$. In particular when $A$ is a linear bounded mapping, $T$ is reduced to the one considered in [17].

Some slight modifications of the proof of [17, Theorem 1] yield the following result.

Theorem 1 Let $(X, d)$ be a complete cone metric space over a solid cone $P$ of a normed vector space $(E,\|\cdot\|)$ and $T: X \rightarrow X$ a quasi-contraction. Assume that $A: P \rightarrow P$ is a nondecreasing and subadditive (i.e., $A(u+v) \preceq A u+A v$ for each $u, v \in P$ ) mapping with $A \theta=\theta$ such that

$$
\sum_{i=0}^{\infty}\left\|A^{i} u\right\|<\infty, \quad \forall u \in P
$$

If $A$ and $B$ are continuous at $\theta$, where $B u=\sum_{i=0}^{\infty} A^{i} u$ for each $u \in P$. Then $T$ has a unique fixed point $x^{*} \in X$, and for each $x_{0} \in X$, the Picard iterative sequence $\left\{x_{n}\right\}$ converges to $x^{*}$, where $x_{n}=T^{n} x_{0}$ for each $n$.

Remark 2 In particular when $A: P \rightarrow P$ is a linear bounded mapping with the spectra radius $r(A)<1$, then (2) is naturally satisfied and $B$ is continuous on $P$ since $B=(I-A)^{-1}$ and $(I-A)^{-1}: P \rightarrow P$ is a linear bounded mapping, where $(I-A)^{-1}$ is the inverse of $I-A$.

The following example shows that there exists some nonlinear mapping $A: P \rightarrow P$ such that (2) is satisfied and $B$ is continuous at $\theta$.

Example 1 Let $E=C_{\mathbb{R}}^{1}[0,1]$ be endowed with the norm $\|u\|=\|u\|_{\infty}+\left\|u^{\prime}\right\|_{\infty}$ and $P=\{u \in$ $E: u(t) \geq 0, \forall t \in[0,1]\}$ which is a non-normal cone [26]. Let $(A u)(t)=a \int_{0}^{t} u^{2} d s$ for each $u \in P$ and each $t \in[0,1]$, where $a>0$.

For each $u \in P$, we have $\left(A^{n} u\right)(t) \leq \frac{(a t)^{n}}{n !}\|u\|_{\infty}^{\frac{1}{2}} \leq \frac{a^{n}}{n !}\|u\|^{\frac{1}{2}}$ for each $t \in[0,1]$ and each $n \geq 1$, and so $\left\|A^{n} u\right\|_{\infty} \leq \frac{a^{n}}{n !}\|u\|^{\frac{1}{2}}$ for each $n \geq 1$. Note that $\left(A^{n} u\right)^{\prime}(t)=a\left(A^{n-1} u\right)^{\frac{1}{2}}(t)$ for each $u \in P$ and each $t \in[0,1]$, then $\left\|\left(A^{n} u\right)^{\prime}\right\|_{\infty} \leq \frac{a^{\frac{n+1}{2}}}{\sqrt{(n-1) !}}\|u\|^{\frac{1}{4}}$ for each $u \in P$ and $n \geq 2$. Thus for each $u \in P$, we have

$$
\left\|A^{n} u\right\|=\left\|A^{n} u\right\|_{\infty}+\left\|\left(A^{n} u\right)^{\prime}\right\|_{\infty} \leq \frac{a^{n}}{n !}\|u\|^{\frac{1}{2}}+\frac{a^{\frac{n+1}{2}}}{\sqrt{(n-1) !}}\|u\|^{\frac{1}{4}}, \quad \forall n \geq 2,
$$

and so

$$
\sum_{i=0}^{\infty}\left\|A^{i} u\right\| \leq\|u\|+2 a\|u\|^{\frac{1}{2}}+\left(\sum_{i=2}^{\infty} \frac{a^{i}}{i !}\right)\|u\|^{\frac{1}{2}}+\left(\sum_{i=2}^{\infty} \frac{a^{\frac{i+2}{2}}}{\sqrt{i !}}\right)\|u\|^{\frac{1}{4}},
$$

which implies that (2) is satisfied since the series $\sum_{i=2}^{\infty} \frac{a^{i}}{i !}$ and $\sum_{i=2}^{\infty} \frac{\frac{i+2}{2}}{\sqrt{i !}}$ are convergent.

Note that $B \theta=\theta$, then for each $u \in P$ we have

$$
\begin{aligned}
\|B u-B \theta\| & =\|B u\| \leq \sum_{i=0}^{\infty}\left\|A^{i} u\right\| \\
& \leq\|u\|+2 a\|u\|^{\frac{1}{2}}+\left(\sum_{i=2}^{\infty} \frac{a^{i}}{i !}\right)\|u\|^{\frac{1}{2}}+\left(\sum_{i=2}^{\infty} \frac{a^{\frac{i+2}{2}}}{\sqrt{i !}}\right)\|u\|^{\frac{1}{4}},
\end{aligned}
$$

which implies that $B$ is continuous at $\theta$. 
Proof of Theorem 1 It follows from (2) that the mapping $B$ is well defined. Clearly, $B(P) \subset P$ and $B \theta=\theta$ since $A(P) \subset(P)$ and $A \theta=\theta$. By (2), we get

$$
\lim _{n \rightarrow \infty}\left\|A^{n} u\right\|=0, \quad \forall u \in P .
$$

Since $A$ and $B$ are commutative,

$$
B A=A B, \quad B(I-A)=(I-A) B=B-A B=I .
$$

We claim that, for all $n \geq 1$,

$$
d\left(x_{i}, x_{j}\right) \preceq B A d\left(x_{0}, x_{1}\right), \quad \forall 1 \leq i, j \leq n .
$$

In the following we shall show this claim by induction.

If $n=1$, then $i=j=1$, and so the claim is trivial.

Assume that (5) holds for $n$. To prove (5) holds for $n+1$, it suffices to show

$$
d\left(x_{i_{0}}, x_{n+1}\right) \preceq B A d\left(x_{0}, x_{1}\right), \quad \forall 1 \leq i_{0} \leq n .
$$

By (1),

$$
d\left(x_{i_{0}}, x_{n+1}\right) \preceq A u ，
$$

where

$$
u \in\left\{d\left(x_{i_{0}-1}, x_{n}\right), d\left(x_{i_{0}-1}, x_{i_{0}}\right), d\left(x_{n}, x_{n+1}\right), d\left(x_{i_{0}-1}, x_{n+1}\right), d\left(x_{n}, x_{i_{0}}\right)\right\} .
$$

Consider the case that $i_{0}=1$.

If $u=d\left(x_{0}, x_{n}\right)$, then by the triangle inequality, the nondecreasing property of $A,(5)$, and (7),

$$
\begin{aligned}
d\left(x_{i_{0}}, x_{n+1}\right) & \preceq A d\left(x_{0}, x_{n}\right) \preceq A\left[d\left(x_{0}, x_{1}\right)+d\left(x_{1}, x_{n}\right)\right] \\
& \preceq A\left[d\left(x_{0}, x_{1}\right)+B A d\left(x_{0}, x_{1}\right)\right]=A(I+B A) d\left(x_{0}, x_{1}\right) \\
& =A\left(I+\sum_{i=1}^{\infty} A^{i}\right) d\left(x_{0}, x_{1}\right)=\operatorname{BAd}\left(x_{0}, x_{1}\right),
\end{aligned}
$$

i.e., (6) holds.

If $u=d\left(x_{0}, x_{1}\right)$, then by $(7)$ and $A(P) \subset P$,

$$
d\left(x_{i_{0}}, x_{n+1}\right) \preceq A d\left(x_{0}, x_{1}\right) \preceq\left(\sum_{i=1}^{\infty} A^{i}\right) d\left(x_{0}, x_{1}\right)=B A d\left(x_{0}, x_{1}\right),
$$

i.e., (6) holds.

If $u=d\left(x_{0}, x_{n+1}\right)$, then by the triangle inequality, the nondecreasing property and subadditivity of $A$, (7), and $A(P) \subset P$,

$$
d\left(x_{i_{0}}, x_{n+1}\right) \preceq A d\left(x_{0}, x_{n+1}\right) \preceq A\left[d\left(x_{0}, x_{1}\right)+d\left(x_{i_{0}}, x_{n+1}\right)\right] \preceq A d\left(x_{0}, x_{1}\right)+A d\left(x_{i_{0}}, x_{n+1}\right),
$$


which implies that

$$
(I-A) d\left(x_{i_{0}}, x_{n+1}\right) \preceq A d\left(x_{0}, x_{1}\right) .
$$

Act on the above inequality with $B$, then by $(4)$ and $B(P) \subset P$,

$$
d\left(x_{i_{0}}, x_{n+1}\right) \preceq B A d\left(x_{0}, x_{1}\right),
$$

i.e., (6) holds.

If $u=d\left(x_{n}, x_{i_{0}}\right)$, then by (5), (7), and $A(P) \subset P$,

$$
\begin{aligned}
d\left(x_{i_{0}}, x_{n+1}\right) & \preceq A d\left(x_{i_{0}}, x_{n}\right) \preceq A^{2} B d\left(x_{0}, x_{1}\right) \\
& =\left(\sum_{i=2}^{\infty} A^{i}\right) d\left(x_{0}, x_{1}\right) \preceq\left(\sum_{i=1}^{\infty} A^{i}\right) d\left(x_{0}, x_{1}\right) \\
& =B A d\left(x_{0}, x_{1}\right),
\end{aligned}
$$

i.e., (6) holds.

If $u=d\left(x_{n}, x_{n+1}\right)$, we set $i_{1}=n-1$, and then by (7),

$$
d\left(x_{i_{0}}, x_{n+1}\right) \preceq A d\left(x_{i_{1}}, x_{n+1}\right) .
$$

Consider the case that $2 \leq i_{0} \leq n$.

If $u=d\left(x_{i_{0}-1}, x_{n}\right)$, or $u=d\left(x_{i_{0}-1}, x_{i_{0}}\right)$, or $d\left(x_{n}, x_{i_{0}}\right)$, then by (5), (7), and $A(P) \subset P$,

$$
\begin{aligned}
d\left(x_{i_{0}}, x_{n+1}\right) & \leq A u \preceq A^{2} B d\left(x_{0}, x_{1}\right) \\
& =\left(\sum_{i=2}^{\infty} A^{i}\right) d\left(x_{0}, x_{1}\right) \preceq\left(\sum_{i=1}^{\infty} A^{i}\right) d\left(x_{0}, x_{1}\right) \\
& =B A d\left(x_{0}, x_{1}\right),
\end{aligned}
$$

i.e., (6) holds.

If $u=d\left(x_{n}, x_{n+1}\right)$, or $u=d\left(x_{i_{0}-1}, x_{n+1}\right)$, we set $i_{1}=n$, or $i_{1}=i_{0}-1 \geq 1$, respectively, and then (8) follows.

From the above discussions of both cases, we have the result that either (6) holds, and so the proof of our claim is complete, or there exists $i_{1} \in\{1,2, \ldots, n\}$ such that (8) holds. For the latter situation, continue in a similar way, and we will have the result that either

$$
d\left(x_{i_{1}}, x_{n+1}\right) \preceq A B d\left(x_{0}, x_{1}\right),
$$

which together with (8) forces

$$
d\left(x_{i_{0}}, x_{n+1}\right) \preceq A^{2} B d\left(x_{0}, x_{1}\right) \preceq A B d\left(x_{0}, x_{1}\right),
$$

i.e., (6) holds, and so the proof of our claim is complete, or there exists $i_{2} \in\{1,2, \ldots, n\}$ such that

$$
d\left(x_{i_{1}}, x_{n+1}\right) \preceq A d\left(x_{i_{2}}, x_{n+1}\right) .
$$


If the above procedure ends by the $k$ th step with $k \leq n-1$, that is, there exist $k+1$ integers $i_{0}, i_{1}, \ldots, i_{k} \in\{1,2, \ldots, n\}$ such that

$$
\begin{aligned}
& d\left(x_{i_{0}}, x_{n+1}\right) \preceq A d\left(x_{i_{1}}, x_{n+1}\right), \\
& d\left(x_{i_{1}}, x_{n+1}\right) \preceq A d\left(x_{i_{2}}, x_{n+1}\right), \\
& d\left(x_{i_{k-1}}, x_{n+1}\right) \preceq A d\left(x_{i_{k}}, x_{n+1}\right), \\
& d\left(x_{i_{k}}, x_{n+1}\right) \preceq B A d\left(x_{0}, x_{1}\right),
\end{aligned}
$$

then by $A(P) \subset P$,

$$
\begin{aligned}
d\left(x_{i_{0}}, x_{n+1}\right) & \preceq A^{k+1} B d\left(x_{0}, x_{1}\right)=\left(\sum_{i=k+1}^{\infty} A^{i}\right) d\left(x_{0}, x_{1}\right) \\
& \preceq\left(\sum_{i=1}^{\infty} A^{i}\right) d\left(x_{0}, x_{1}\right)=B A d\left(x_{0}, x_{1}\right)
\end{aligned}
$$

i.e. (6) holds, and so the proof of our claim is complete.

If the above procedure continues more than $n$ steps, then there exist $n+1$ integers $i_{0}, i_{1}, i_{n} \in\{1,2, \ldots, n\}$ such that

$$
\begin{aligned}
& d\left(x_{i_{0}}, x_{n+1}\right) \preceq \operatorname{Ad}\left(x_{i_{1}}, x_{n+1}\right), \\
& d\left(x_{i_{1}}, x_{n+1}\right) \preceq \operatorname{Ad}\left(x_{i_{2}}, x_{n+1}\right), \quad \ldots, \\
& d\left(x_{i_{n-1}}, x_{n+1}\right) \preceq \operatorname{Ad}\left(x_{i_{n}}, x_{n+1}\right) .
\end{aligned}
$$

It is clear that $i_{0}, i_{1}, i_{n} \in\{1,2, \ldots, n\}$ implies there exist two integers $k, l \in\{0,1,2, \ldots, n\}$ with $k<l$ such that $i_{k}=i_{l}$, then by the nondecreasing property of $A$ and (9),

$$
d\left(x_{i_{k}}, x_{n+1}\right) \preceq A^{l-k} d\left(x_{i_{l}}, x_{n+1}\right)=A^{l-k} d\left(x_{i_{k}}, x_{n+1}\right),
$$

and so

$$
\left(I-A^{l-k}\right) d\left(x_{i_{k}}, x_{n+1}\right) \preceq \theta .
$$

Set $B_{1} u=\sum_{i=0}^{\infty} A^{i(l-k)} u$ for each $u \in P$. By (2), $B_{1}: P \rightarrow P$ is well defined. Clearly, $B_{1} \theta=\theta$ and

$$
B_{1}\left(I-A^{l-k}\right)=\left(I-A^{l-k}\right) B_{1}=B_{1}-A^{l-k} B_{1}=I .
$$

Act on (10) with $B_{1}$, then by (11), $B_{1}(P) \subset P$ and $B_{1} \theta=\theta$ we get $d\left(x_{i_{k}}, x_{n+1}\right)=\theta$, and hence (6) holds by (9). The proof of our claim is complete.

For each $1<m<n$ and each $x_{0} \in X$, set

$$
C\left(x_{0}, m, n\right)=\left\{d\left(T^{i} x_{0}, T^{j} x_{0}\right): m \leq i, j \leq n\right\} .
$$


From (1), it follows that, for each $u \in C\left(x_{0}, m, n\right)$, there exists some $v \in C\left(x_{0}, m-1, n\right)$ such that $u \preceq A v$. Consequently for all $1<m<n$, there exist $u_{i} \in C\left(x_{0}, m-i, n\right)(i=1,2, \ldots, m-1)$ such that

$$
d\left(x_{m}, x_{n}\right) \preceq A u_{1} \preceq A^{2} u_{2} \preceq \cdots \preceq A^{m-1} u_{m-1},
$$

since $A$ is nondecreasing. Note that $u_{m-1} \in C\left(x_{0}, 1, n\right)$, then by (5),

$$
u_{m-1} \preceq \operatorname{BAd}\left(x_{0}, x_{1}\right),
$$

and so by (12),

$$
d\left(x_{m}, x_{n}\right) \preceq B A^{m} d\left(x_{0}, x_{1}\right), \quad \forall 1<m<n .
$$

It follows from (3) that $A^{m} d\left(x_{0}, x_{1}\right) \stackrel{\|\cdot\|}{\rightarrow} \theta(m \rightarrow \infty)$, and hence $B A^{m} d\left(x_{0}, x_{1}\right) \stackrel{\|\cdot\|}{\rightarrow} \theta(m \rightarrow \infty)$ since $B$ is continuous at $\theta$. This together with Lemma 2 implies that $B A^{m} d\left(x_{0}, x_{1}\right) \stackrel{w}{\rightarrow} \theta$ $(m \rightarrow \infty)$. Moreover, by (13) and Lemma 1 , we get

$$
d\left(x_{m}, x_{n}\right) \stackrel{w}{\rightarrow} \theta \quad(n>m \rightarrow \infty)
$$

i.e., $\left\{x_{n}\right\}$ is a Cauchy sequence of $X$. Therefore by the completeness of $X$, there exists some $x^{*} \in X$ such that $x_{n} \stackrel{\tau_{d}}{\rightarrow} x^{*}(n \rightarrow \infty)$, i.e.,

$$
d\left(x_{n}, x^{*}\right) \stackrel{w}{\rightarrow} \theta \quad(n \rightarrow \infty)
$$

By (1),

$$
d\left(T x^{*}, x^{*}\right) \preceq d\left(x_{n+1}, T x^{*}\right)+d\left(x_{n+1}, x^{*}\right) \preceq A u+d\left(x_{n+1}, x^{*}\right), \quad \forall n,
$$

where $u \in\left\{d\left(x_{n}, x^{*}\right), d\left(x_{n}, x_{n+1}\right), d\left(x^{*}, T x^{*}\right), d\left(x_{n}, T x^{*}\right), d\left(x^{*}, x_{n+1}\right)\right\}$.

If $u=d\left(x_{n}, x^{*}\right)$, or $u=d\left(x_{n}, x_{n+1}\right)$, or $u=d\left(x^{*}, x_{n+1}\right)$, then by (14), (15), (16), Lemma 1 , and Lemma 3 , we get $d\left(T x^{*}, x^{*}\right)=\theta$ since $A$ is continuous at $\theta$.

If $u=d\left(x^{*}, T x^{*}\right)$, then by (16),

$$
(I-A) d\left(x^{*}, T x^{*}\right) \preceq d\left(x_{n+1}, x^{*}\right), \quad \forall n,
$$

and hence by (15), for each $\epsilon \in \operatorname{int} P$, there exists $n_{0}$ such that, for each $n \geq n_{0}$,

$$
(I-A) d\left(x^{*}, T x^{*}\right) \preceq d\left(x_{n+1}, x^{*}\right) \ll \epsilon,
$$

which implies that

$$
(I-A) d\left(x^{*}, T x^{*}\right) \preceq \theta .
$$

Act on (18) with $B$, then by $B(P) \subset P$ and $B \theta=\theta$ we get $d\left(T x^{*}, x^{*}\right)=\theta$. 
If $u=d\left(x_{n}, T x^{*}\right)$, then by the triangle inequality, the nondecreasing property, and subadditivity of $A$ and (16), we have

$$
\begin{aligned}
d\left(T x^{*}, x^{*}\right) & \preceq d\left(x_{n+1}, x^{*}\right)+A d\left(x_{n}, T x^{*}\right) \\
& \preceq d\left(x_{n+1}, x^{*}\right)+A\left[d\left(x_{n}, x^{*}\right)+d\left(x^{*}, T x^{*}\right)\right] \\
& \preceq d\left(x_{n+1}, x^{*}\right)+A d\left(x_{n}, x^{*}\right)+A d\left(x^{*}, T x^{*}\right), \quad \forall n,
\end{aligned}
$$

and so

$$
(I-A) d\left(x^{*}, T x^{*}\right) \preceq d\left(x_{n+1}, x^{*}\right)+A d\left(x_{n}, x^{*}\right), \quad \forall n .
$$

Thus it follows from (15) and Lemma 3 that (17) holds for each $\epsilon \in \operatorname{int} P$ since $A$ is continuous at $\theta$. Consequently, we get (18). Act on (18) with $B$, then by $B(P) \subset P$ and $B \theta=\theta$ we get $d\left(T x^{*}, x^{*}\right)=\theta$. This shows that $x^{*}$ is a fixed point of $T$.

If $x$ is another fixed point of $T$, then by (1),

$$
d\left(x, x^{*}\right)=d\left(T x, T x^{*}\right) \preceq A u,
$$

where $u \in\left\{d\left(x, x^{*}\right), d(x, T x), d\left(x^{*}, T x^{*}\right), d\left(x, T x^{*}\right), d\left(x^{*}, T x\right)\right\}$. If $u=d(x, T x)$, or $u=d\left(x^{*}, T x^{*}\right)$, then $u=\theta$, and hence $d\left(x, x^{*}\right)=\theta$. If $u=d\left(x, x^{*}\right)$, or $u=d\left(x, T x^{*}\right)$ or $u=d\left(x^{*}, T x\right)$, then we must have $u=d\left(x, x^{*}\right)$, and hence $(I-A) d\left(x, x^{*}\right) \preceq \theta$. Act on it with $B$, then by $B(P) \subset P$ and $B \theta=\theta$ we get $d\left(x, x^{*}\right)=\theta$. This shows $x^{*}$ is the unique fixed point of $T$. The proof is complete.

The following example shows the usability of Theorem 1.

Example 2 Let $E$ and $P$ be the same ones as those in Example 1 and $X=P$. Define a mapping $d: X \times X \rightarrow P$ by

$$
d(x, y)= \begin{cases}\theta, & x=y, \\ x+y, & x \neq y .\end{cases}
$$

Clearly, $(X, d)$ is a complete cone metric space.

Let $(T x)(t)=\int_{0}^{t} x^{\frac{1}{2}}(s) d s$ and $(A x)(t)=\sqrt{2}(T x)(t)$ for each $x \in X$ and each $t \in[0,1]$.

Clearly, $A: P \rightarrow P$ is a nondecreasing mapping with $A \theta=\theta$, and $A$ is continuous at $\theta$. From Example 1 we know that (2) is satisfied and $B$ is continuous at $\theta$. For each $u, v \in P$, we have $(A(u+v))(t)=\sqrt{2} \int_{0}^{t}(u(s)+v(s))^{\frac{1}{2}} d s \leq \sqrt{2} \int_{0}^{t}\left(u(s)^{\frac{1}{2}}+v(s)^{\frac{1}{2}}\right) d s=(A u)(t)+(A v)(t)$ for each $t \in[0,1]$, and so $A(u+v) \preceq A u+A v$ for each $u, v \in P$, i.e., $A$ is subadditive.

Note that $(T x)(t)+(T y)(t) \int_{0}^{t}\left(x^{\frac{1}{2}}(s)+y^{\frac{1}{2}}(s)\right) d s=\int_{0}^{t}\left(x(s)+y(s)+2 x^{\frac{1}{2}}(s) y^{\frac{1}{2}}(s)\right)^{\frac{1}{2}} d s \leq$ $\sqrt{2} \int_{0}^{t}(x(s)+y(s))^{\frac{1}{2}} d s=\sqrt{2}(T(x+y))(t)$ for each $t \in[0,1]$ and each $x, y \in X$, i.e., $T x+T y \preceq$ $\sqrt{2} T(x+y)$ for each $x, y \in P$, then

$$
d(T x, T y)= \begin{cases}\theta=A d(x, y), & x=y, \\ T x+T y \preceq \sqrt{2} T(x+y)=A d(x, y), & x \neq y,\end{cases}
$$

i.e., (1) is satisfied with $u=d(x, y)$. 
Hence all the assumptions of Theorem 1 are satisfied, and so $T$ has a unique fixed point. In fact, $\theta$ is the unique fixed point of $T$.

\section{Remark 3}

(i) Since in Example 2 the underlying mapping $A$ is nonlinear, we can conclude that any of the theorems in $[12-15,17]$ cannot cope with Example 2.

(ii) Let $u_{0}(t)=\cos ^{2} t$ for each $t \in[0,1]$ in Example 2. Clearly, $u_{0} \in \operatorname{int} P$ and $\left(A u_{0}\right)(t)=\sqrt{2} \int_{0}^{t} \cos s d s=\sqrt{2} \sin t$ for each $t \in[0,1]$. Take $t_{0}=\frac{\pi}{4}$, we have $\left(A u_{0}\right)\left(t_{0}\right)=1>\frac{1}{2}=u_{0}\left(t_{0}\right)$, and so $A u_{0} \npreceq u_{0}$, i.e., $(I-A) u_{0} \notin P$. Note that it is necessarily assumed that $(I-A)(\operatorname{int} P) \subset \operatorname{int} P$ in [16], then Theorem 2 of [16] is not applicable.

In what follows, we shall show that the subadditivity of $A$ assumed in Theorem 1 could be removed in the case that (1) is satisfied for $u=d(x, y)$.

Theorem 2 Let $(X, d)$ be a complete cone metric space over a solid cone $P$ of a normed vector space $(E,\|\cdot\|)$ and $T: X \rightarrow X$. Assume that

$$
d(T x, T y) \preceq A d(x, y), \quad \forall x, y \in X,
$$

where $A: P \rightarrow P$ is a nondecreasing mapping with $A \theta=\theta$ such that (2) is satisfied. If $A$ and $B$ are continuous at $\theta$, where $B u=\sum_{i=0}^{\infty} A^{i} u$ for each $u \in P$. Then $T$ has a unique fixed point $x^{*} \in X$, and for each $x_{0} \in X$, the Picard iterative sequence $\left\{x_{n}\right\}$ converges to $x^{*}$.

Proof By the nondecreasing property of $A$ and (19), we have

$$
d\left(x_{n}, x_{n+1}\right) \preceq A d\left(x_{n-1}, x_{n}\right) \preceq A^{2} d\left(x_{n-2}, x_{n-1}\right) \preceq \cdots \preceq A^{n} d\left(x_{0}, x_{1}\right), \quad \forall n,
$$

and so, by the triangle inequality,

$$
\begin{aligned}
d\left(x_{n}, x_{m}\right) & \leq \sum_{i=n}^{m-1} d\left(x_{i}, x_{i+1}\right) \preceq \sum_{i=n}^{m-1} A^{i} d\left(x_{0}, x_{1}\right) \\
& =A^{n}\left(\sum_{i=n}^{m-1} A^{i}\right) d\left(x_{0}, x_{1}\right)=B A^{n} d\left(x_{0}, x_{1}\right), \quad \forall m>n .
\end{aligned}
$$

Since $B$ is continuous at $\theta$, it follows from (3) that $B A^{n} d\left(x_{0}, x_{1}\right) \stackrel{\|\cdot\|}{\rightarrow} \theta(n \rightarrow \infty)$, which together with Lemma 2 implies that $B A^{n} d\left(x_{0}, x_{1}\right) \stackrel{w}{\rightarrow} \theta(n \rightarrow \infty)$. Moreover, by (20) and Lemma 1, we get

$$
d\left(x_{m}, x_{n}\right) \stackrel{w}{\rightarrow} \theta \quad(m>n \rightarrow \infty)
$$

i.e., $\left\{x_{n}\right\}$ is a Cauchy sequence of $X$. Therefore by the completeness of $X$, there exists some $x^{*} \in X$ such that (15) is satisfied. By the triangle inequality and (19), we get

$$
d\left(x^{*}, T x^{*}\right) \preceq d\left(x^{*}, x_{n+1}\right)+d\left(T x_{n}, T x^{*}\right) \preceq d\left(x^{*}, x_{n+1}\right)+A d\left(x_{n}, x^{*}\right), \quad \forall n,
$$


which together with (15), Lemma 1 , and Lemma 3 implies that $p\left(x^{*}, T x^{*}\right)=\theta$ since $A$ is continuous at $\theta$. Hence $x^{*}$ is a fixed point of $T$. Let $x$ be another fixed point of $T$, then by (19),

$$
d\left(x, x^{*}\right)=d\left(T x, T x^{*}\right) \preceq A d\left(x, x^{*}\right),
$$

and so $(I-A) d\left(x, x^{*}\right) \preceq \theta$. Act on it with $B$, then by $B(P) \subset P$ and $B \theta=\theta$ we get $d\left(x, x^{*}\right)=\theta$. This shows $x^{*}$ is the unique fixed point of $T$. The proof is complete.

\section{Competing interests}

The authors declare that they have no competing interests.

\section{Authors' contributions}

The authors have contributed in obtaining the new results presented in this article. All authors read and approved the final manuscript.

\section{Author details}

${ }^{1}$ Department of Mathematics, Jiangxi University of Finance and Economics, Nanchang, 330013, China. ${ }^{2}$ School of Statistics, Jiangxi University of Finance and Economics, Nanchang, 330013, China. ${ }^{3}$ Research center of Applied Statistics, Jiangxi University of Finance and Economics, Nanchang, 330013, China.

\section{Acknowledgements}

The work was supported by Natural Science Foundation of China (11161022), Natural Science Foundation of Jiangxi Province (20114BAB211006, 20122BAB201015), Educational Department of Jiangxi Province (GJJ12280, GJJ13297, KJLD14034), Program for Excellent Youth Talents of JXUFE (201201) and Candidate of Jiangxi Youth Scientist.

Received: 20 May 2014 Accepted: 11 July 2014 Published: 28 July 2014

\section{References}

1. Huang, LG, Zhang, X: Cone metric spaces and fixed point theorems of contractive mappings. J. Math. Anal. Appl. 332, 1468-1476 (2007)

2. Rezapour, S, Hamlbarani, R: Some notes on the paper 'Cone metric spaces and fixed point theorems of contractive mappings'. J. Math. Anal. Appl. 345, 719-724 (2008)

3. Janković, S, Kadelburg, Z, Radenović, S: On the cone metric space: a survey. Nonlinear Anal. 74, 2591-2601 (2011)

4. Agarwal, RP: Contraction and approximate contraction with an application to multi-point boundary value problems. J. Comput. Appl. Math. 9, 315-325 (1983)

5. Jiang, S, Li, Z: Extensions of Banach contraction principle to partial cone metric spaces over a non-normal solid cone. Fixed Point Theory Appl. 2013, Article ID 250 (2013)

6. Li, Z, Jiang, S: Common fixed point theorems of contractions in partial cone metric spaces over nonnormal cones. Abstr. Appl. Anal. 2014, Article ID 653841 (2014)

7. Cakali, H, Sonmez, A, Genc, C: On an equivalence of topological vector space valued cone metric spaces and metric spaces. Appl. Math. Lett. 25, 429-433 (2012)

8. Du, W-S: A note on cone metric fixed point theory and its equivalence. Nonlinear Anal. 72, 2259-2261 (2010)

9. Kadelburg, Z, Radenović, S, Rakočević, V: A note on the equivalence of some metric and cone metric fixed point results. Appl. Math. Lett. 24, 370-374 (2011)

10. Feng, Y, Mao, W: The equivalence of cone metric spaces and metric spaces. Fixed Point Theory 11, $259-264$ (2010)

11. Ćirić, LB: A generalization of Banach's contraction principle. Proc. Am. Math. Soc. 45, 267-273 (1974)

12. Ilić, D, Rakočević, V: Quasi-contracion on a cone metric space. Appl. Math. Lett. 22, 728-731 (2009)

13. Kadelburg, Z, Radenović, S, Rakočević, V: Remarks on 'Quasi-contraction on a cone metric space'. Appl. Math. Lett. 22, 1674-1679 (2009)

14. Rezapour, S, Haghi, RH, Shahzad, N: Some notes on fixed points of quasi-contraction maps. Appl. Math. Lett. 23 498-502 (2010)

15. Gajić, L, Rakočević, V: Quasi-contractions on a nonnormal cone metric space. Funct. Anal. Appl. 46, 75-79 (2012)

16. Arandjelović, ID, Kečkić, DJ: On nonlinear quasi-contractions on TVS-cone metric spaces. Appl. Math. Lett. 24, 1209-1213 (2011)

17. Li, Z, Jiang, S: Quasi-contractions restricted with linear bounded mappings in cone metric spaces. Fixed Point Theory Appl. 2014, Article ID 87 (2014)

18. Haghi, RH, Rezapour, S, Shahzad, N: Some fixed point generalizations are not real generalizations. Nonlinear Anal. 74, 1799-1803 (2011)

19. Rezapour, S, Derafshpour, M, Shahzad, N: Best proximity points of cyclic $\phi$-contractions in ordered metric spaces. Fixed Point Theory Appl. 2010, Article ID 946178 (2010)

20. Derafshpour, M, Rezapour, S, Shahzad, N: Best proximity points of cyclic $\varphi$-contractions on reflexive Banach space. Topol. Methods Nonlinear Anal. 37, 193-202 (2011)

21. Rezapour, S, Haghi, RH, Rhoades, B: Some results about $T$-stability and almost $T$-stability. Fixed Point Theory 12 , 179-186 (2011) 
22. Haghi, RH, Rezapour, S, Shahzad, N: On fixed points of quasi-contraction type multifunctions. Appl. Math. Lett. 25 843-846 (2012)

23. Rezapour, S, Shahzad, N: Common fixed points of $(\phi, \psi)$-type contractive maps. Appl. Math. Lett. 25, 959-962 (2012)

24. Ghorbanian, V, Rezapour, S, Shahzad, N: Some ordered fixed point results and the property (P). Comput. Math. Appl. 63, 1361-1368 (2012)

25. Haghi, RH, Postolache, M, Rezapour, S: On T-stability of the Picard iteration for generalized $\varphi$-contraction mappings. Abstr. Appl. Anal. 2012, Article ID 658971 (2012)

26. Deimling, K: Nonlinear Functional Analysis. Springer, Berlin (1985)

doi:10.1186/1687-1812-2014-165

Cite this article as: Jiang and Li: Nonlinear quasi-contractions in non-normal cone metric spaces. Fixed Point Theory and Applications 2014 2014:165.

Submit your manuscript to a SpringerOpen ${ }^{\circ}$ journal and benefit from:

- Convenient online submission

- Rigorous peer review

- Immediate publication on acceptance

- Open access: articles freely available online

- High visibility within the field

- Retaining the copyright to your article

Submit your next manuscript at $>$ springeropen.com 